\title{
Teachers' Burnout during COVID-19 Pandemic in Spain: Trait Emotional Intelligence and Socioemotional Competencies
}

\author{
Laura Sánchez-Pujalte ${ }^{1}$, Diego Navarro Mateu ${ }^{1,2}$, Edgardo Etchezahar ${ }^{1,3,4}$ and Talía Gómez Yepes ${ }^{1,3, * \text { (D) }}$ \\ 1 Faculty of Education, International University of Valencia, 46002 Valencia, Spain; \\ marialaura.sanchez@campusviu.es (L.S.-P.); diego.navarro@campusviu.es (D.N.M.); \\ edgardoetchezahar@psi.uba.ar (E.E.) \\ 2 Department of Inclusive Education, Faculty of Education, Catholic University of Valencia, \\ 46110 Valencia, Spain \\ 3 Faculty of Psychology, University of Buenos Aires, Buenos Aires 1207, Argentina \\ 4 National Scientific and Technical Research Council, Buenos Aires 1428, Argentina \\ * Correspondence: talia.gomez@campusviu.es
}

check for updates

Citation: Sánchez-Pujalte, L.; Mateu, D.N.; Etchezahar, E.; Gómez Yepes, T. Teachers' Burnout during COVID-19 Pandemic in Spain: Trait Emotional Intelligence and Socioemotional Competencies. Sustainability 2021, 13, 7259. https://doi.org/10.3390/ su13137259

Academic Editors: Gabriela Topa,

Xuesong Zhai and Juan

Carlos Pérez-González

Received: 28 May 2021

Accepted: 23 June 2021

Published: 29 June 2021

Publisher's Note: MDPI stays neutral with regard to jurisdictional claims in published maps and institutional affiliations.

Copyright: (c) 2021 by the authors. Licensee MDPI, Basel, Switzerland. This article is an open access article distributed under the terms and conditions of the Creative Commons Attribution (CC BY) license (https:// creativecommons.org/licenses/by/ $4.0 /)$.

\begin{abstract}
The aim of this research is to recognize the burnout levels in a group of high school teachers that exercised their profession during the COVID-19 pandemic, looking forward to examining the correlation between burnout levels, trait emotional intelligence and socioemotional competencies (Autonomy, Regulation, Prosocial Behaviour and Empathy). The study counted with a sample of 430 high school teachers from multiple regions of Spain. The participants' age was between 25 and 60, and the gender distribution was $53.72 \%$ for men and $46.28 \%$ for women. We used the Spanish version of the Maslach Burnout Inventory (MBI), the Trait Meta-Mood Scale (TMMS-24) and the Socioemotional Competences Scale (SCS). The main results indicated that teachers showed high levels of burnout dimensions, with women being the most affected, reaching higher levels in comparison to men. It was also observed that the older and more experienced professionals showed lower levels of burnout. Finally, statistically significant negative relations were found between emotional intelligence and burnout levels, as well as their association with the teacher's socioemotional competencies. The analysis argues the possible consequences of stress during the pandemic and, correspondingly, the need for promoting protective approaches that embrace emotional intelligence and socioemotional competencies.
\end{abstract}

Keywords: burnout; teachers; trait emotional intelligence; socioemotional competencies; empathy; emotional autonomy; regulation; prosociality

\section{Introduction}

Since 14 March 2020, the Spanish population has gone through different quarantine phases, which have varied in their restrictions according to the region, passing through border closures, social distancing, and the suspension of presential academic activities overtaken by virtualization, among other consequences [1]. After more than a year of restrictions, the well-being of citizens in general, and teachers particularly, has been affected according to different studies [2-4]. In this regard, although efforts have been made to train teachers through online learning platforms, and work-family reconciliation has been [5], this modal change implied a series of challenges when developed in a hostile, complex and unprecedented context [6]. Therefore, it is necessary to develop sustainable work environments and policies, which provide well-being to teachers in different aspects (social, emotional, physical), which would be reflected not only in the improvement of their productivity-even in extreme situations, as is the case of job development during the COVID-19 pandemic [7-9]; it would also help to prevent pathologies associated with the teaching function, such as burnout due to prolonged exposures of stress, factors and 
individual characteristics [10], such as age and years of experience [11,12], gender of teachers $[13,14]$ and poorly or unsustainable working conditions [15].

The virtualization of education brought an important increase in the teachers' working hours due to the need for training and updating in ICT, higher student activity and the combination of working hours and fewer hours of rest [16], having an impact on the emergence and increase of negative emotions and extreme wear and tear [4]. Unanswered questions about the pandemic, such as how long it will lasting and if it will be possible to return to normal life, as well as when the workday ends, when it will be possible to see family and friends, when it will be possible to going out without risk of being infected, when the vaccine will arrive, etc., added to the constant exposure to a flow of information and reduction of rest hours, could also be negatively affecting the well-being of teachers [2] and educational processes [3]. Education is a key factor in social development that is constantly facing many challenges. Teachers are one of the pillars of education since they play an essential role in the teaching and learning processes [17]. Contextual conditions such as unsustainable work environments [15], as well as personal characteristics, can lead to prolonged episodes of stress and exhaustion [18]. Teachers are considered to be especially vulnerable not only to physical problems, such as headaches, but also to anxiety and stress problems, which can lead to sick leave, lack of commitment and even absenteeism as consequences of burnout [19].

\subsection{Teachers' Burnout Syndrome}

Burnout syndrome is defined as a persistent negative emotional state characterized by a general feeling of psychological discomfort and low levels of self-esteem, motivation and professional commitment. It occurs as a result of prolonged stress caused by the professional environment [20]. Burnout syndrome emerges on three main dimensions: Cynicism, Emotional Exhaustion and Self-Efficacy. The first dimension refers to an apathetic or insensitive response to professional duties [21]. The second refers to a feeling of not being able to do more, finding oneself physically and emotionally exhausted. The third and final dimension refers to the professional's perception of their own ability to face their professional challenges, which can lead to feelings of failure, incompetence, and low self-esteem [22]. Different studies carried out on burnout syndrome in teachers establish the conjunction of different factors related to individual differences, Emotional Exhaustion caused by the increase and level of stressors such as increased deadlines, increased workload [23,24], the decrease in professional autonomy, interpersonal conflicts with co-workers and family members [25] due to the impossibility of differentiating workspace hours from leisure or rest $[26,27]$, among others. In the educational field, teachers can go through periods of burnout due to changes in their professional conditions -as is the case of the change in circumstances due to the COVID-19 pandemic [15], which can cause changes in motivation, producing attrition and weakening the ability to regulate internal emotional responses [28].

\subsection{Trait Emotional Intelligence and SocioEmotional Competencies as Protectives Factors of Burnout}

As a protective factor against these types of problems, it has been pointed out that trait emotional intelligence has a significant effect on the ability of individuals to cope with burnout [3,28]. According to different authors [4,29-31], emotional intelligence refers to a set of skills related to the processing of emotional and affective information, which are divided into three large dimensions. On the one hand, Emotional Clarity refers to the way people believe they perceive their emotions. Low levels in this dimension would affect teachers with their own mood, leading them to have intrusive thoughts that often lead to highly stressful situations [32,33]. The psychological maladjustment that occurs by not being able to modify emotional states would bring negative consequences in their work environment, such as poor exercise of teaching practice, dropouts or abandonment as their psychosocial well-being can be affected [28,34]. In addition, the Attention dimension implies the degree to which people believe they are paying attention to their feelings and emotions. Being affected would imply that teachers decrease their performance 
and increase distraction that often leads to the abandonment of daily tasks. Finally, the Repair dimension, which is defined as the belief that people have about their ability to interrupt and regulate their negative emotional states and to prolong the positive ones. As this dimension is affecting the teaching population, it could lead to burnout, as it seems a diminution of the strategies and capacity to regulate stress [30,31]. This dimension, in optimal conditions, would lead to the intellectual and emotional growth of subjects. Having high levels of the three dimensions of emotional intelligence could be a protective factor for the burnout experienced by teachers in complex times (such as a pandemic). There is general agreement about conceptualizing emotional intelligence in two different ways $[35,36]$. On the one hand, a model that analyses the construct as a personality trait and, on the other hand, an ability model based on information processing and emotion reasoning [37,38]. This study is approached from the trait EI model.

Another protective factor against burnout is socioemotional competencies, which are defined as the abilities of individuals to regulate their emotions and emotional behaviour [39]. According to the authors [40,41], there are four competencies that stand out particularly for the protection from burnout: Emotional Regulation, Prosociality, Emotional Autonomy and Empathy. Emotional regulation can be defined as any strategy aimed at maintaining, increasing or suppressing an affective state in progress [40]. Within Emotional Regulation, self-control activities are included along with self-regulation behaviours in which self-comforting or self-reassurance, emotional control and relaxation would be found. As long as teachers are able to regulate their emotions and make decisions for themselves, they will feel committed and motivated to improve their professional competence and carry out actions that favour their profession, which would help their training process and the students' educational process [41]. Emotional Autonomy, understood as the ability to feel, think and make decisions for oneself, allows teachers to become their own "authority of reference" [42,43]. Emotional autonomy is situated at an equidistant balance point between emotional dependence and affective detachment. Two other socioemotional competencies are central to tackling teacher burnout. On one hand, Prosociality, which refers to voluntary actions carried out for the benefit of others, such as sharing, donating, caring for, comforting and helping $[44,45]$. On the other hand, Empathy, which is defined as the emotional reaction produced by and congruently with the other's emotional state, implies the engaging of perspective as a cognitive dimension, and sympathy, or empathic concern, as an affective dimension [46]. Both competencies can be affected by burnout, presenting detachment, indifference and the inability to respond emotionally to the needs of their peers and students [39]. Socioemotional competencies would be directly related to burnout by the diminishing work commitment, causing a negative impact on teachers' attitudes towards their work: if teachers are able to regulate their emotions and make decisions for themselves, they will feel committed and motivated to improve their professional competence and carry out voluntary actions in their workplaces and towards their colleagues [44]. On the contrary, emotionally poor teachers will be more affected by burnout, which will lead them to be more likely to reject professional learning opportunities and show detachment towards their work and relationships with their colleagues and students $[18,20]$.

\subsection{Research Hypothesis}

Based on the literature described above, the following hypotheses were formulated:

1. According to the consequences that have been observed in different contexts in terms of high stress in workers because of the COVID-19 pandemic [7-9], it is proposed to analyse the levels of burnout in a sample of secondary school teachers. Based on these findings, the following hypothesis is proposed:

Hypothesis 1 (H1). There are high levels in the dimensions of burnout in most teachers. 
2. Since previous research has shown that working women tend to have higher levels of burnout compared to men $[13,14]$. It is proposed to analyse the differences in burnout levels according to the gender of the participants. Based on these findings, the following hypothesis is proposed:

Hypothesis 2 (H2). There are statistically significant gender differences in the teachers' burnout levels.

3. Previous studies have indicated that age and years of experience $[11,12]$ are two variables that may be related to burnout levels. Considering these findings, it is proposed:

Hypothesis 3 (H3). Age and years of experience show a negative association with burnout levels.

4. Different studies have shown that trait emotional intelligence can be a protective factor against burnout in workers [44,45]. It is proposed to investigate the relationships between the dimensions of burnout and the emotional intelligence of the participants. Based on these findings, the following hypothesis is proposed:

Hypothesis 4 (H4). The dimensions of burnout are negatively related to the dimensions of teachers' emotional intelligence.

5. Different studies have indicated that certain socioemotional competencies can favour the reduction of burnout in workers [42,43]; therefore, it is proposed to study whether the variables are related. Based on these findings, the following hypothesis is proposed:

Hypothesis 5 (H5). The socioemotional competencies (Empathy, Regulation, Prosocial Behaviour and Emotional Autonomy) of teachers are negatively related to the dimensions of burnout.

\section{Materials and Methods}

\subsection{Participants}

The sample was taken from 430 high school teachers from different autonomous communities of Spain (Table 1) who worked during the COVID-19 pandemic in 2020/2021, aged 25-60 $\left(M_{\text {age }}=41.40 ; S D=11.07\right)$. The gender distribution was $53.72 \%(n=231)$ for men and $46.28 \%(n=199)$ for women.

Table 1. Autonomous communities sample distribution.

\begin{tabular}{ccc}
\hline Autonomous Community & $f$ & $\%$ \\
\hline Catalunya & 54 & 12.6 \\
Madrid & 68 & 15.8 \\
Andalucía & 84 & 19.5 \\
País Vasco & 63 & 14.7 \\
Galicia & 61 & 14.2 \\
Valencia & 68 & 15.8 \\
Castilla y León & 32 & 7.4 \\
Total & 430 & 100.0 \\
\hline
\end{tabular}

\subsection{Instruments}

Burnout levels were evaluated with the Maslach Burnout Inventory (MBI) [19] adapted for teachers [27]. The MBI has demonstrated adequate reliability and validity of the threefactor structure in different studies. Cronbach's alpha for the MBI scales ranged from 0.88 to 0.90 for Emotional Exhaustion, 0.74 to 0.76 for Depersonalization and 0.72 to 0.76 for personal achievement. Adequate convergent and discriminant validity of the original MBI was established as the measure was developed $[10,18]$. The scale has 22 items with answer choices on a six-point Likert-type scale (from $0=$ Never to $6=$ Always/Every day), on three scales: Emotional Exhaustion (feeling of not being able to do more, finding oneself physically and emotionally exhausted), Cynicism (criticism and loss of interest as an attitude 
towards teaching) and Professional Efficacy (feelings of personal realization). The reliability reported by Cronbach's alpha for the three dimensions was adequate $(0.78 \leq \alpha \leq 0.86)$.

Emotional Intelligence was evaluated with the Spanish version of the TMMS-24 [32,33], which is composed of 24 items that make up three dimensions: Attention, Emotional Clarity and Emotional Regulation, with a five-point response format Likert-type scale ( 1 = Strongly disagree, to $5=$ Strongly agree). The original Spanish version of the scale analyses the descriptive statistics of the items, and the internal consistency of the three dimensions $(0.60<\alpha<0.83)$, as well as the construct validity and its external validity through the relations with two criterion variables (Beck's Depression Inventory and Satisfaction with Life Scale). Regarding the psychometric properties of our study, an adequate reliability was observed for each dimension (Attention: $\alpha=0.79$; Clarity: $\alpha=0.77$ and Regulation: $\alpha=0.80)$.

Socioemotional Competencies were evaluated with the Socioemotional Competences Inventory (SCI) [29]. The original scale was studied and analysed through a pilot study where 446 subjects participated, and the descriptive measures of the items were analysed. Subsequently, the final version of the questionnaire was analysed in 509 subjects, in whom descriptive statistics and the reliability of the dimensions $(0.60<\alpha<0.87)$ were analysed, as well as its construct validity and the concurrent validity of the test with the Inventory of Bar-On Emotional Quotient (EQ-i) $(0.32<r<0.78)$ [29]. For this study, four competencies were analysed: Emotional Autonomy $(\alpha=0.80)$, Regulation $(\alpha=0.81)$, Empathy $(\alpha=0.76)$ and Prosociality $(\alpha=0.71)$. All the dimensions have a Likert-type evaluation format from 1 (Strongly disagree) to 5 (Strongly agree).

Sociodemographic data was collected through an ad hoc questionnaire (age, gender, place of residence and years of experience as a teacher).

\subsection{Procedure}

The data was collected on an online survey delivered via social media to several groups of teachers in different Autonomous Communities of Spain. The main condition for being able to participate in the study was that the teacher had taught classes in secondary schools during 2020 and 2021. Teachers were given the appropriate instructions and were assured that their participation was optional and that their responses would remain anonymous. The average time estimated to complete the questionnaire was between 15-20 min.

\subsection{Data Analysis}

The statistical analysis was carried out with IBM SPSS 24.0 (Armonk, NY, USA) [47]. First, to test H1, the descriptive statistics of teachers' burnout levels were analysed (frequencies and percentages). Subsequently, to test the $\mathrm{H} 2$ about gender differences in burnout dimensions, a set of student's t-test was applied as well as Cohen's $d$ for effect size. A series of ANOVAs was conducted to test the $\mathrm{H} 3$ to find out whether there were differences between the burnout dimensions according to age and years of teaching experience using a Tukey B post hoc contrast. The Pearson's correlation was used to analyze the relationship between the dimensions of burnout with the emotional intelligence dimensions (Attention, Clarity and Repair) (H4) and with the socioemotional competencies (Regulation, Empathy, Prosociality and Autonomy) (H5).

\section{Results}

\subsection{Teachers' Burnout}

Initially, for testing $\mathrm{H} 1$ three groups of participants were set up to establish low, medium, and high levels in the three dimensions of burnout: Emotional Exhaustion (Low: $\leq 18$; Medium: 19-26; High: 27 $\leq$ ); Cynicism (Low: $\leq 5$; Medium: 6-9; High: 10 $\leq$ ) and Professional Efficacy: (Low: 40 $\leq$; Medium: 34-39; High: $\leq 33$ ). Table 2 shows the frequencies and percentage of teachers' burnout levels, according to their scores on MBI. 
Table 2. Levels of burnout experienced by teachers.

\begin{tabular}{ccccccc}
\hline & \multicolumn{2}{c}{$\begin{array}{c}\text { Emotional } \\
\text { Exhaustion }\end{array}$} & \multicolumn{2}{c}{ Cynism } & \multicolumn{2}{c}{$\begin{array}{c}\text { Proffesional } \\
\text { Efficacy }\end{array}$} \\
\hline Low & $f$ & \% & $f$ & \% & $f$ & $\%$ \\
Medium & 120 & 27.9 & 165 & 38.4 & 298 & 69.3 \\
High & 51 & 11.9 & 106 & 24.6 & 32 & 7.4 \\
\hline
\end{tabular}

A significant number of teachers were found with high levels of Emotional Exhaustion (60.2\%) and low levels of Professional Efficacy (69.3\%). Regarding Cynicism, a relatively similar distribution was observed between low, medium, and high levels.

\subsection{Relationship between Burnout and Teachers' Gender}

Regarding H2, on gender differences were observed in the Professional Efficacy dimensions $\left(t_{(422)}=3.701 ; p<0.001\right.$; Cohen's $\left.d=0.361\right)$, with women $(\mathrm{M}=27.16$; $\mathrm{DT}=13.26)$ being the ones who obtained higher scores compared to men $(\mathrm{M}=22.48 ; \mathrm{DT}=12.61)$ and in Cyni$\operatorname{cism}\left(t_{(422)}=-3.294 ; p<0.001 ;\right.$ Cohen's d $\left.=0.322\right)$, with the women $(\mathrm{M}=6.27 ; \mathrm{DT}=5.24)$ being the ones who obtained lower scores compared to men $(M=7.93$; DT $=5.04)$. No statistically significant differences were observed between gender and Emotional Exhaustion.

\subsection{Relationship between Burnout and Age and Years of Experience}

In addition, regarding $\mathrm{H} 3$ differences were found in Emotional Exhaustion with respect to age $\left(\mathrm{F}_{(429)}=10.089 ; p<0.001\right)$ and the years of experience of the participants $\left(\mathrm{F}_{(429)}=8.421 ; p<0.001\right)$. Regarding age, the Tukey B post hoc contrast indicated two groupings considering Emotional Exhaustion levels: High Levels $\left(\mathrm{M}_{\mathrm{age}}=39.49\right)$ and Low $/$ Medium Levels $=\left(\mathrm{M}_{\mathrm{age}}=44.31\right)$. Concerning the years of experience, the same pattern was observed through the Tukey B post hoc contrast, which indicated two groupings reckoning to the levels of Emotional Exhaustion: High Levels $\left(M_{\text {age }}=10.36\right)$ and Low /Medium Levels ( $\left.\mathrm{M}_{\mathrm{age}}=14.44\right)$.

Furthermore, differences were found in Professional Efficacy regarding age $\left(\mathrm{F}_{(429)}=13.605\right.$; $p<0.001)$ and the years of experience of the participants $\left(F_{(429)}=16.692 ; p<0.001\right)$. As to age: the Tukey $\mathrm{B}$ post hoc contrast indicated two groupings considering the Professional Efficacy levels: High/Medium Levels $($ Mage $=45.94)$ and Low Levels $\left(M_{\text {age }}=39.63\right)$. Regarding the years of experience, the same pattern is observed through the Tukey B post hoc contrast, which indicated two groupings regarding the levels of Professional Efficacy: High/Medium Levels $\left(\mathrm{M}_{\mathrm{age}}=15.85\right)$ and Low Levels $\left(\mathrm{M}_{\mathrm{age}}=10.12\right)$.

Finally, differences were found in Cynicism regarding age $\left(\mathrm{F}_{(429)}=15.562 ; p<0.001\right)$ and the years of experience of the participants $\left(\mathrm{F}_{(429)}=15.268 ; p<0.001\right)$. As to age, the Tukey B post hoc contrast indicated two groupings regarding Professional Efficacy levels: High/Medium Levels $\left(\mathrm{M}_{\mathrm{age}}=39.13\right)$ and Low $\left(\mathrm{M}_{\mathrm{age}}=46.05\right)$. Observing the years of experience, the same pattern is seen through the Tukey B post hoc contrast, which indicated two groupings regarding the levels of Professional Efficacy: High/Medium Levels $\left(\mathrm{M}_{\mathrm{age}}=9.82\right)$ and Low Levels $\left(\mathrm{M}_{\mathrm{age}}=14.81\right)$.

No statistically significant differences were found between the levels of burnout dimensions on the different autonomous communities.

\subsection{Relationship between Burnout and Trait Emotional Inteligence and SocioEmotional Competencies}

Regarding H4 the Table 3 shows the results for the relationship between Emotional Exhaustion and Clarity $(\mathrm{r}=-0.259 ; p<0.001)$ and Repair $(\mathrm{r}=-0.187 ; p<0.01)$, the Cynicism dimension with Repair $(r=-0.254 ; p<0.001)$ and Professional Efficacy with Clarity $(\mathrm{r}=0.349 ; p<0.001)$. 
Table 3. Relationship between burnout dimensions, trait emotional intelligence and socioemotional competencies.

\begin{tabular}{|c|c|c|c|c|c|c|c|c|c|c|}
\hline & 1 & 2 & 3 & 4 & 5 & 6 & 7 & 8 & 9 & 10 \\
\hline 1. Emotional Exhaustion & 0.78 & $0.315^{* *}$ & $-0.509 * *$ & -0.132 & $-0.259 * *$ & -0.187 * & $-0.374 * *$ & $-0.257^{* *}$ & -0.134 & -0.153 \\
\hline 2. Cynicism & & 0.81 & $-0.211^{* *}$ & -0.050 & -0.151 & $-0.254^{* *}$ & $-0.308^{* *}$ & $-0.445^{* *}$ & $-0.172 *$ & $-0.241^{* *}$ \\
\hline 3. Professional Efficacy & & & 0.86 & 0.007 & $0.349 * *$ & 0.155 & $0.242 * *$ & $0.207^{*}$ & $0.231^{* *}$ & 0.058 \\
\hline 4. Attention & & & & 0.79 & $0.414^{* *}$ & $0.367^{* *}$ & 0.054 & $0.152 *$ & 0.070 & 0.075 \\
\hline 5. Clarity & & & & & 0.77 & $0.533 * *$ & $0.199^{* *}$ & $0.295 * *$ & $0.266^{* *}$ & 0.193 ** \\
\hline 6. Repair & & & & & & 0.80 & $0.365^{* *}$ & 0.313 ** & $0.166^{*}$ & 0.268 ** \\
\hline 7. Regulation & & & & & & & 0.81 & $0.264^{* *}$ & $0.298^{* *}$ & 0.406 ** \\
\hline 8. Empathy & & & & & & & & 0.76 & $0.240 * *$ & 0.004 \\
\hline 9. Prosociality & & & & & & & & & 0.71 & 0.109 \\
\hline 10. Emotional Autonomy & & & & & & & & & & 0.80 \\
\hline
\end{tabular}

Note. Cronbach's alpha in diagonal. ${ }^{* *} p<0.001 ;{ }^{*} p<0.01$.

Lastly, considering H5, the relation between the teachers' burnout levels and socioemotional competencies such as Regulation, Empathy, Prosociality and Autonomy were analysed (Table 3).

As can be seen in Table 3, statistically significant relationships were found between Emotional Exhaustion and Regulation $(r=-0.374 ; p<0.001)$ and Empathy $(r=-0.257$; $p<0.001)$. Regarding Cynicism, relationships were observed with Regulation $(r=-0.308$; $p<0.001)$, Empathy $(r=-0.445 ; p<0.001)$, Prosociality $(r=-0.172 ; p<0.01)$ and Emotional Autonomy $(r=-0.241 ; p<0.001)$. Finally, Professional Efficacy is related to Regulation $(r=0.242 ; p<0.001)$, Empathy $(r=0.207 ; p<0.01)$ and Prosociality $(r=0.231 ; p<0.001)$.

\section{Discussion}

This study examined how teachers' burnout is related to gender, age and years of experience and how emotional intelligence and socioemotional competencies are factors that are directly related to the burnout levels of secondary school teachers. All the hypotheses proposed in our study were confirmed. First, a significant number of teachers were found with high levels of Emotional Exhaustion (60.2\% of the total sample) and low Professional Efficacy (69.3\%). Regarding Cynicism, a relatively similar distribution is observed between low, medium, and high levels [2]. These results confirm that most teachers present high levels of burnout, as suggested by different authors [3,48,49].

Regarding gender, the second hypothesis established that women show higher scores than men in Professional Efficacy and lower in Cynicism, as observed in previous studies [20,21]. Regarding Emotional Exhaustion, no differences were observed in this study according to gender, contrary to what was observed in previous studies [50,51], indicating that women have higher levels than men. This may be due to the fact that the context of the COVID-19 pandemic affected both genders equally in this dimension of burnout [15].

The third hypothesis of this study was also confirmed. As found in previous studies [26,27], factors such as age and years of experience showed a negative association with burnout. Younger teachers with fewer years of experience are more vulnerable, obtaining high scores in Emotional Exhaustion and Cynicism [21] and lower levels of Professional Efficiency in comparison to older teachers with more years of experience. According to different authors [51,52], these relationships could be due to the fact that more experienced teachers (older, more years of experience) have developed coping strategies and, therefore, are more emotionally protected to face professional challenges. In addition, the age and years of experience of teachers have been related to less burnout and the use of stress managemen strategies [26].

The fourth hypothesis, which negatively relates burnout to teachers' levels of emotional intelligence, is also confirmed: teachers who present high levels of emotional intelligence tend to present low levels of burnout. Our results indicate relationships between the dimensions of burnout with Clarity and Repair. In this sense, authors such as $\mathrm{O}^{\prime}$ Boyle et al. [4] argue that both dimensions are relevant for the management of emotions since they provide protection against prolonged high levels of stress. However, no differences were found with Attention, an aspect that may be due to a saturation of this 
specific dimension on these pandemic times [2]. In summary, at higher levels of emotional intelligence, the lower risk of burnout by teachers [29]. Burnout, therefore, is directly linked to the performance of professional activity and personal life, as it develops in work contexts with negative psychological impact $[19,20,49]$.

The last hypothesis proposes that some socioemotional competencies of teachers (Empathy, Regulation, Prosociality and Emotional Autonomy) are related to their levels of burnout. The background shows that Empathy and Prosociality play a key role in improving work performance and prevent against teacher absenteeism, which can be observed in their relationships with Professional Efficacy $[49,53]$. Both socioemotional competencies are essential to increase interpersonal skills at work, as well as Regulation, which is negatively related to the three dimensions of burnout, since it is a protective factor against adverse situations, as is the case of the COVID-19 pandemic [15], as well as Emotional Autonomy [42,54,55]. The role of socioemotional competencies is critical for teachers to be able to practice their profession successfully and face diverse and changing challenges both in the workplace and in daily life. Difficulties with socioemotional competencies negatively influence job performance and general well-being in the short term. High levels play a prominent role as intervening factors in the reduction of burnout symptoms and also as protective factors that improve the affective climate in the classroom [3,13], interaction with students, parents, workmates and educational authorities, among others $[1,56]$.

\section{Conclusions}

This study provides evidence on the relationship between burnout with teachers' age and years of experience, identifying some aspects that could help teachers in training and new teachers to improve and develop their socioemotional skills and trait emotional intelligence, being aware of the importance of training in socioemotional competencies would help the teaching staff to prepare for their professional career and their alternatives to enhance strengths and abilities. If teachers can have healthier management of their emotional experience, they will be able to perceive skills as internal strengths that may help them with their career adaptability. Appropriate emotion regulation strategies can support and strengthen teachers' ability to prepare for a changing and stressful work environment and make it a sustainable environment. Teachers' stress can impair their personal and professional competence, as well as compromising their ability to work. The adverse emotions experienced during the COVID-19 pandemic may have resulted in increased levels of burnout, which particularly affects teaching staff. However, this aspect cannot be known with certainty because we do not have a study prior to the pandemic that can indicate whether burnout levels were low or medium. Although, with some limitations, the results of this study confirm the idea that burnout syndrome is related to age, gender and years of experience as teachers, as well as their levels of trait emotional intelligence and socioemotional competencies. The loss of the face-to-face routine was presented as a negative element for the teachers since it implied an increase in the teaching load, an aspect that denotes the need to review the training process and establish effective indicators and parameters in this area, with the objective to not saturate the teaching staff with extracurricular activities that become stressors, as these can lead to burnout and poor performance.

In short, the trait emotional intelligence and socioemotional competencies of teachers are revealed, both inside and outside the classroom; therefore, the use of strategies that allow their development will favour the reduction or elimination of possible stressors and their negative consequences for the well-being. From this point of view, and assuming that the work environment is one of the main aspects to consider for the development of healthier education professionals, promoting the well-being of teachers becomes a key factor for their own sustainability and productivity, helping the prevention of pathologies associated with teaching. Although the efficacy of these protective factors has already been explored, there is still a long way to go after a pandemic such as the one we have experienced over these years. 
The present study has several limitations to consider. First, only self-report measures were used. Therefore, we could not control the effect of bias that could have magnified the observed relationships between the variables. Furthermore, as different authors suggest, using self-report measures, trait EI was analysed, which represents behavioural dispositions and perceptions about emotions. Future studies could also investigate the Ability of EI to analyse the cognitive/conscious component and its relationships with the dimensions of burnout. Second, the research did not contemplate mental health aspects prior to the COVID-19 pandemic, which could have influenced the variables analysed, such as states of exhaustion that the teachers had already been dragging on. A future research line could be to analyse the role of emotion regulation in the professional decision-making process. The regulation of emotions affects the general decision-making process, such as the individual experience of anger or feelings of frustration, which are widespread feelings in teachers with high levels of stress. Longitudinal studies could also contribute to the analysis of the impact of emotion regulation on the abandonment of work, family relationship problems, reluctance to return to work after COVID-19, need for psychological treatments, among others.

Author Contributions: Conceptualization, L.S.-P., D.N.M., E.E. and T.G.Y.; data curation, L.S.-P., D.N.M., E.E. and T.G.Y.; formal analysis, L.S.-P., D.N.M., E.E. and T.G.Y.; investigation, L.S.-P., D.N.M., E.E. and T.G.Y.; methodology, L.S.-P., D.N.M., E.E. and T.G.Y.; resources, L.S.-P., D.N.M., E.E. and T.G.Y.; writing—original draft, L.S.-P., D.N.M., E.E. and T.G.Y.; writing—review and editing, L.S.P., D.N.M., E.E. and T.G.Y. All authors have read and agreed to the published version of the manuscript.

Funding: This research received no external funding.

Institutional Review Board Statement: The study was conducted according to the guidelines of the Declaration of Helsinki and approved by the Ethics Committee.

Informed Consent Statement: Informed consent was obtained from all subjects involved in the study.

Data Availability Statement: The data that support the findings of this study are available from the corresponding author upon reasonable request.

Conflicts of Interest: The authors declare no conflict of interest.

\section{References}

1. Tejedor, S.; Cervi, L.; Tusa, F.; Parola, A. Educación en tiempos de pandemia: Reflexiones de alumnos y profesores sobre la enseñanza virtual universitaria en España, Italia y Ecuador. Rev. Lat. Comun. Soc. 2020, 78, 1-21. [CrossRef]

2. Etchevers, M.J.; Garay, C.J.; Putrino, N.; Grasso, J.; Natalí, V.; Helmich, N. Salud Mental en Cuarentena. Relevamiento del Impacto Psicológico a los 7-11, 50-55 y 115-124 Días de Cuarentena en Población Argentina; Observatorio de Psicología Social Aplicada: Buenos Aires, Argentina, 2020.

3. Mérida-López, S.; Extremera, N. When pre-service teachers' lack of occupational commitment is not enough to explain intention to quit: Emotional intelligence matters! Rev. Psicodidáctica 2020, 25, 52-58. [CrossRef]

4. O'Boyle, E.H.; Humphrey, R.H.; Pollack, J.M.; Hawver, T.H.; Story, P.A. The relation between emotional intelligence and job performance: A meta-analysis. J. Organiz. Behav. 2011, 32, 788-818. [CrossRef]

5. Borgmann, L.-S.; Kroll, L.E.; Müters, S.; Rattay, P.; Lampert, T. Work-Family Conflict, Self-Reported General Health and WorkFamily Reconciliation Policies in Europe: Results from the European Working Conditions Survey 2015. SSM-Popul. Health 2019, 9 , 100465. [CrossRef] [PubMed]

6. Duran Vila, N.I. El Teletrabajo y la conciliación con el entorno de convivencia familiar durante la Pandemia COVID-19. In Revista de Investigacion Psicologica Especial; Instituto de Investigacion Interaccion y Postgrado de Psicologia: La Paz, Bolivia, 2020; pp. 68-72.

7. Martínez-López, J.A.; Lázaro-Pérez, C.; Gómez-Galán, J. Burnout among Direct-Care Workers in Nursing Homes during the COVID-19 Pandemic in Spain: A Preventive and Educational Focus for Sustainable Workplaces. Sustainability 2021, $13,2782$. [CrossRef]

8. Tecău, A.S.; Petrișor, C.; Lixăndroiu, R.C.; Chițu, I.B.; Brătucu, G. Impact of the COVID-19 Crisis on Heavy Work Investment in Romania. Amfiteatru Econ. 2020, 22, 1049-1067.

9. Ivancevic, S.; Ivanovic, T.; Maricic, M.; Cudanov, M. Student Heavy Work Investment, Burnout, and Their Antecedents: The Case of Serbia. Amfiteatru Econ. 2020, 22, 1182-1205.

10. Ferradás, M.d.M.; Freire, C.; García-Bértoa, A.; Núñez, J.C.; Rodríguez, S. Teacher Profiles of Psychological Capital and Their Relationship with Burnout. Sustainability 2019, 11, 5096. [CrossRef] 
11. Brewer, E.W.; Shapard, L. Employee Burnout: A Meta-Analysis of the Relationship Between Age or Years of Experience. Hum. Resour. Dev. Rev. 2004, 3, 102-123. [CrossRef]

12. Zabel, R.H.; Kay Zabel, M. Revisiting Burnout Among Special Education Teachers: Do Age, Experience, and Preparation Still Matter? Teacher Education and Special Education. Teach. Educ. Spec. Educ. 2010, 24, 128-139. [CrossRef]

13. Bartkowiak, G.; Krugiełka, A.; Kostrzewa-Demczuk, P.; Dachowski, R.; Gałek, K. Styles of Coping with Stress as a Factor Influencing Professional Burnout among Professional Officers of the Polish Army in the Context of Their Age. Sustainability 2021, 13, 3953. [CrossRef]

14. Bayani, A.A.; Bagheri, H.; Bayani, A. Influence of Gender, Age, and Years of teaching experience on Burnout. Ann. Biol. Res. 2013, 4, 239-243.

15. Malureanu, A.; Panisoara, G.; Lazar, I. The Relationship between Self-Confidence, Self-Efficacy, Grit, Usefulness, and Ease of Use of eLearning Platforms in Corporate Training during the COVID-19 Pandemic. Sustainability 2021, 13, 6633. [CrossRef]

16. Mishra, D.L.; Gupta, D.T.; Shree, D.A. Online Teaching-Learning in Higher Education during Lockdown Period of COVID-19 Pandemic. Int. J. Educ. Res. Open 2020, 1, 100012. [CrossRef]

17. Watts, J.; Robertson, N. Burnout in university teaching staff: A systematic literature review. Educ. Res. 2011, 53, 33-50. [CrossRef]

18. Papastilianou, A.; Kaila, M.; Polychronopoulus, M. Teachers' burnout, depression, role ambiguity and conflict. Soc. Psychol. Educ. 2009, 12, 295-314. [CrossRef]

19. Maslach, C.; Jackson, S.E. Maslach Burnout Inventory Manual, 2nd ed.; Consulting Psychologists Press: Palo Alto, CA, USA, 1986.

20. Maslach, C.; Schaufeli, W.B.; Leiter, M.P. Job burnout. Annu. Rev. Psychol. 2001, 52, 397-422. [CrossRef]

21. Bakker, A.B.; Demerouti, E.; Verbeke, W. Using the job demands-resources model to predict burnout and performance. Hum. Resour. Manag. 2004, 41, 83-104. [CrossRef]

22. Smeds, M.R.; Janko, M.R.; Allen, S.; Amankwah, K.; Arnell, T.; Ansari, P.; Balters, M.; Hess, D.; Ferguson, E.; Jackson, P.; et al Burnout and its Relationship with Perceived Stress, Self-Efficacy, Depression, Social Support, and Programmatic Factors in General Surgery Residents. Am. J. Surg. 2020, 219, 907-912. [CrossRef]

23. Bang, H.; Reio, T.G. Examining the role of cynicism in the relationships between burnout and employee behavior. Rev. Psicol. Del Trab. Las Organ. 2017, 33, 217-227. [CrossRef]

24. Castellani, V.; Perinelli, E.; Gerbino, M.; Caprara, G.V. Positive orientation and interpersonal styles. Pers. Individ. Differ. 2016, 98, 229-234. [CrossRef]

25. Caprara, G.V.; Pastorelli, C. Early emotional instability, prosocial behaviour, and aggression: Some methodological aspects. Eur. J. Personal. 1993, 7, 19-36. [CrossRef]

26. Koehler, J.; Mishra, P. Introducing Technological Pedagogical Knowledge. In Handbook of Technological Pedagogical Content Knowledge for Educators; Routledge: New York, NY, USA, 2008.

27. Ansley, B.M.; Houchins, D.E.; Varjas, K.; Roach, A.; Patterson, D.; Hendricke, R. The impact of an online stress intervention on burnout and teacher efficacy. Teach. Teach. Educ. 2021, 98, 103251. [CrossRef]

28. Alarcon, G.M. A meta-analysis of burnout with job demands, resources, and attitudes. J. Vocat. Behav. 2011, 79, 549-562. [CrossRef]

29. Johnson, S.J.; Holdsworth, L.; Hoel, H.; Zapf, D. Customer stressors in service organizations: The impact of age on stress management and burnout. Eur. J. Work. Organ. Psychol. 2013, 22, 318-330. [CrossRef]

30. Johnson, S.J.; Machowski, S.; Holdsworth, L.; Kern, M.; Zapf, D. Age, emotion regulation strategies, burnout, and engagement in the service sector: Advantages of older workers. Rev. Psicol. Del Trab. Las Organ. 2017, 33, 205-216. [CrossRef]

31. Mérida-López, S.; Extremera, N. Emotional intelligence and teacher burnout: A systematic review. Int. J. Educ. Res. 2017, 85, 121-130. [CrossRef]

32. Mayer, J.D.; Salovey, P. What is emotional intelligence? In Emotional Development and Emotional Intelligence: Implications for Educators; Salovey, P., Sluyter, D., Eds.; Basic Books: New York, NY, USA, 1997; pp. 3-31.

33. Fernandez-Berrocal, P.; Extremera, N.; Ramos, N. Validity and Reliability of the Spanish Modified Version of the Trait Meta-Mood Scale. Psychol. Rep. 2004, 94, 751-755. [CrossRef]

34. Mayer, J.D.; Caruso, D.R.; Salovey, P. The Ability Model of Emotional Intelligence: Principles and Updates. Emot. Rev. 2016, 8 , 290-300. [CrossRef]

35. Boden, M.T.; Berenbaum, H. What you are feeling and why: Two distinct types of emotional clarity. Pers. Individ. Dif. 2011, 51, 652-656. [CrossRef] [PubMed]

36. O'Connor, P.J.; Hill, A.; Kaya, M.; Martin, B. The measurement of emotional intelligence: A critical review of the literature and recommendations for researchers and practitioners. Front. Psychol. 2019, 10, 1116. [CrossRef] [PubMed]

37. Siegling, A.B.; Saklofske, D.H.; Petrides, K.V. Measures of ability and trait emotional intelligence. In Measures of Personality and Social Psychological Constructs; Boyle, G.J., Matthews, G., Saklofske, D.H., Eds.; Academic Press: San Diego, CA, USA, 2015.

38. Pérez-González, J.C.; Saklofske, D.H.; Mavroveli, S. Editorial: Trait Emotional Intelligence: Foundations, Assessment, and Education. Front. Psychol. 2020, 11, 608. [CrossRef]

39. Pérez, J.C.; Petrides, K.V.; Furnham, A. Measuring trait emotional intelligence. In Emotional Intelligence: An International Handbook; Schulze, R., Roberts, R.D., Eds.; Hogrefe \& Huber: Cambridge, UK, 2015; pp. 181-201.

40. Boden, M.T.; Thompson, R.J.; Dizén, M.; Berenbaum, H.; Baker, J.P. Are emotional clarity and emotion differentiation related? Cogn. Emot. 2013, 27, 961-978. [CrossRef] 
41. Eisenberg, N.; Eggum, N.D.; Di Giunta, L. Empathy-Related Responding: Associations with Prosocial Behavior, Aggression, and Intergroup Relations. Soc. Issues Policy Rev. 2010, 4, 143-180. [CrossRef]

42. Mikulic, I.M.; Crespi, M.; Radusky, P. Construcción y validación del inventario de competencias socioemocionales para adultos (ICSE). Interdisciplinaria 2015, 32, 307-329. [CrossRef]

43. Gross, J.J. Emotion Regulation: Past, present, future. Cogn. Emot. 1999, 13, 551-573. [CrossRef]

44. Brackett, M.A.; Palomera, R.; Mojsa-Kaja, J.; Reyes, M.R.; Salovey, P. Emotion-regulation ability, burnout, and job satisfaction among British secondary-school teachers. Psychol. Sch. 2010, 47, 410-417. [CrossRef]

45. Colomeischi, A.A. Teachers Burnout in Relation with Their Emotional Intelligence and Personality Traits. Procedia Soc. Behav. Sci. 2015, 180, 1067-1073. [CrossRef]

46. Collie, R.J.; Shapka, J.D.; Perry, N.E.; Martin, A.J. Teachers' beliefs about social-emotional learning: Identifying teacher profiles and their relations with job stress and satisfaction. Learn. Instr. 2015, 39, 148-157. [CrossRef]

47. Hernández Sampieri, R.; Mendoza Torres, C.P. Metodología de la Investigación; McGraw-Hill: Mexico City, Mexico, 2018.

48. McIntyre, T.M.; McIntyre, S.E.; Francis, D. Educator Stress: An Occupational Health Perspective; Springer International Publishing: London, UK, 2017.

49. Wang, M.; Burlacu, G.; Truxillo, D.; James, K.; Yao, X. Age differences in feedback reactions: The roles of employee feedback orientation on social awareness and utility. J. Appl. Psychol. 2015, 100, 1296-1308. [CrossRef]

50. Bilge, F. Examining the burnout of academics in relation to job satisfaction and other factors. Soc. Behav. Personal. Int. J. 2006, 34, 1151-1160. [CrossRef]

51. Ghorpade, J.; Lackritz, J.; Singh, G. Burnout and Personality: Evidence From Academia. J. Career Assess. 2017, 15, 240-256. [CrossRef]

52. Lackritz, J. Exploring burnout among university faculty: Incidence, performance, and demographic issues. Teach. Teach. Educ. 2004, 20, 713-729. [CrossRef]

53. Panari, C.; Tonelli, M.; Mazzetti, G. Emotion Regulation and Employability: The Mediational Role of Ambition and a Protean Career among Unemployed People. Sustainability 2020, 12, 9347. [CrossRef]

54. Perpiñà Martí, G.; Sidera Caballero, F.; Serrat Sellabona, E. Does Emotional Intelligence Have an Impact on Linguistic Competences? A Primary Education Study. Sustainability 2020, 12, 10474. [CrossRef]

55. Chernyshenko, O.; Kankaraš, M.; Drasgow, F. Social and Emotional Skills for Student Success and Well-Being: Conceptual Framework for the OECD Study on Social and Emotional Skills; OECD Education Working Papers; OECD: Paris, France, 2018 ; Volume 173.

56. Perrenoud, P. Diez Nuevas Competencias Para Enseñar; Grao: Barcelona, Spain, 2004. 